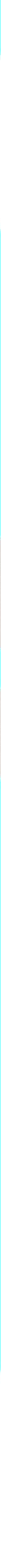




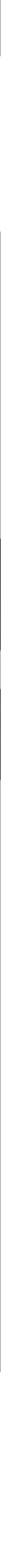




\section{Toxoplasmose: \\ - que seu gato tem a ver com isso?}

Maria Verônyca Coelho Melo

Alessandra Marinho da Silva

Felipe Dourado de Aragão Pinheiro

Dalyla Uchôa Cavalcante

Nívia Barbosa Rocha

Silvia Helena Lobo Sousa

Alexsandre Fernandes Ribeiro

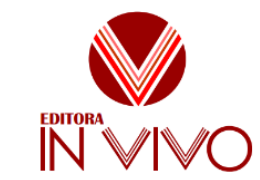

Fortaleza - CE

2020 
2020 by Editora In Vivo

Copyright (C) Editora In Vivo

Copyright do Texto (C) 20200 autor

Copyright da Edição (c) 2020 Editora In Vivo

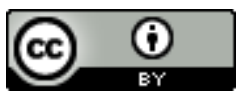

Esta obra está licenciada com uma Licença Creative Commons Atribuição 4.0 Internacional (CC BY 4.0).

O conteúdo desta obra e seus dados em sua forma, correção e confiabilidade são de responsabilidade exclusiva do autor. Permitido o download da obra e o compartilhamento desde que sejam atribuídos créditos ao autor, mas sem a possibilidade de alterá-la de nenhuma forma ou utilizá-la para fins comerciais.

\section{Editor Chefe}

Dr. Everton Nogueira Silva

\section{Conselho Editorial}

Dr. Aderson Martins Viana Neto

MSc. Cícero Francisco de Lima

MSc. Erivelton de Souza Nunes

Dr. Fágner Cavalcante Patrocínio dos Santos

MSc. Filomena Nádia Rodrigues Bezerra

MSc. Henrique Nogueira Silva

Dr. Isaac Neto Goes da Silva

Dra. Lina Raquel Santos Araújo

Dr. Victor Hugo Vieira Rodrigues

MSc. Yuri Lopes Silva

Dados Internacionais de Catalogação na Publicação - CIP

\section{M528t Melo, Maria Verônyca Coelho}

Toxoplasmose [cartilha eletrônica]: o que seu gato tem a ver com isso? / Maria Verônyca Coelho Melo... [et al.]. Fortaleza:

Editora In Vivo, 2020.

$42 \mathrm{p}$.

Bibliografia.

ISBN: 978-65-991243-1-0

Doi: $10.47242 / 978-65-991243-1-0$

1. Toxoplasmose. 2. Parasitologia. 3. Enfermagem em ambiente virtual. I. Título.

CDD 616.96 


\section{HOMENAGEM}

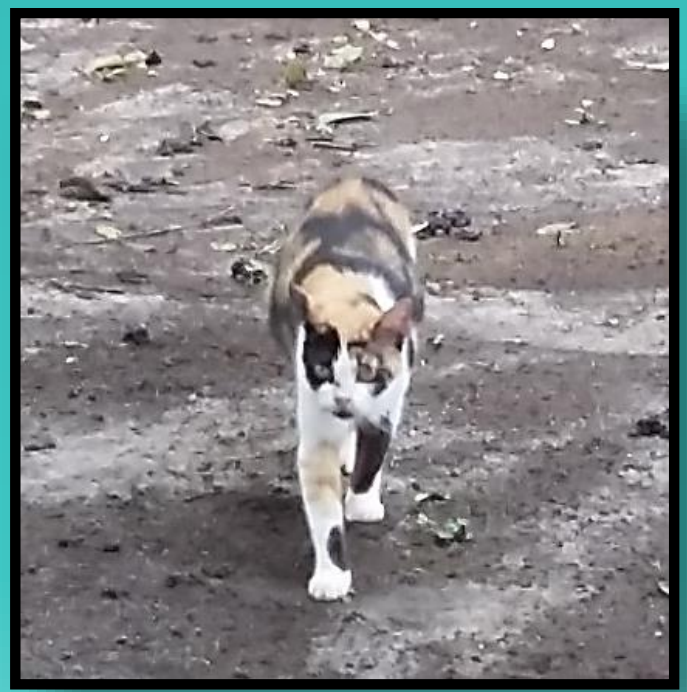

Homenagem a Nectarina, gata mais linda da Universidade Estadual do Ceará, que viveu um período entre alunos, professores e funcionários. 

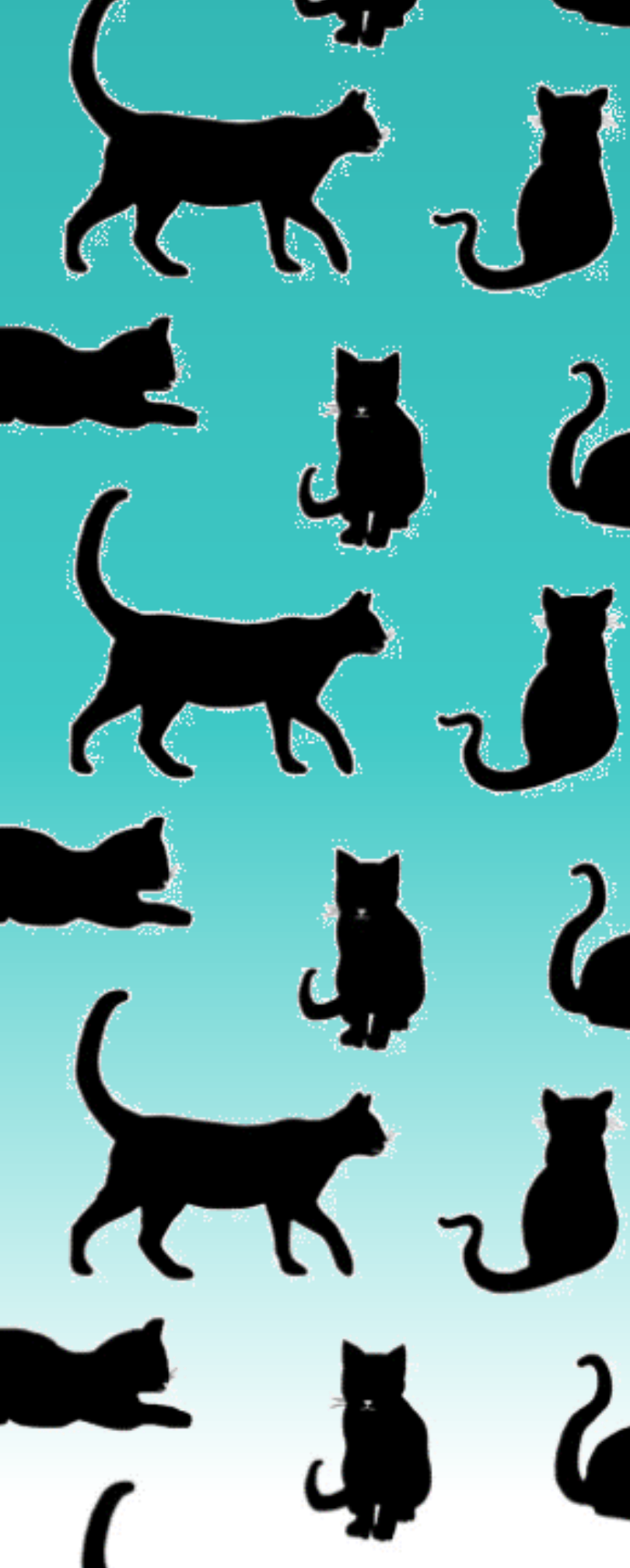


\section{APRESENTAÇÃO}

A cartilha educativa foi confeccionada como atividade desenvolvida na disciplina de parasitologia do curso de enfermagem em ambiente virtual (EaD). Os ambientes virtuais são considerados como um espaço de construção do conhecimento por meio do desenvolvimento de atividades educativas, mediadas pelo uso de Tecnologias de Informação e Comunicação. Portanto a confecção da cartilha é uma atividade de alta complexidade onde o aluno tem que construir o seu próprio saber. Procuramos trabalhar de forma didática para que as atividades sejam mais atraentes. 


\section{SUMÁRIO}

O que é a Toxoplasmose??? ............ 11

Era uma vez um parasita ................ 13

Cara - crachá ........................... 18

Saiba como identificar e a qual seriedade dos sintomas................................... 21

Como seu médico confirma ............. 24

De olho nos cuidados e fazendo o tratamento

28

MEU GATO NÃO É O VILÃO .............. 31

Referências Bibliográficas ............... 32

Autores ................................. 35 

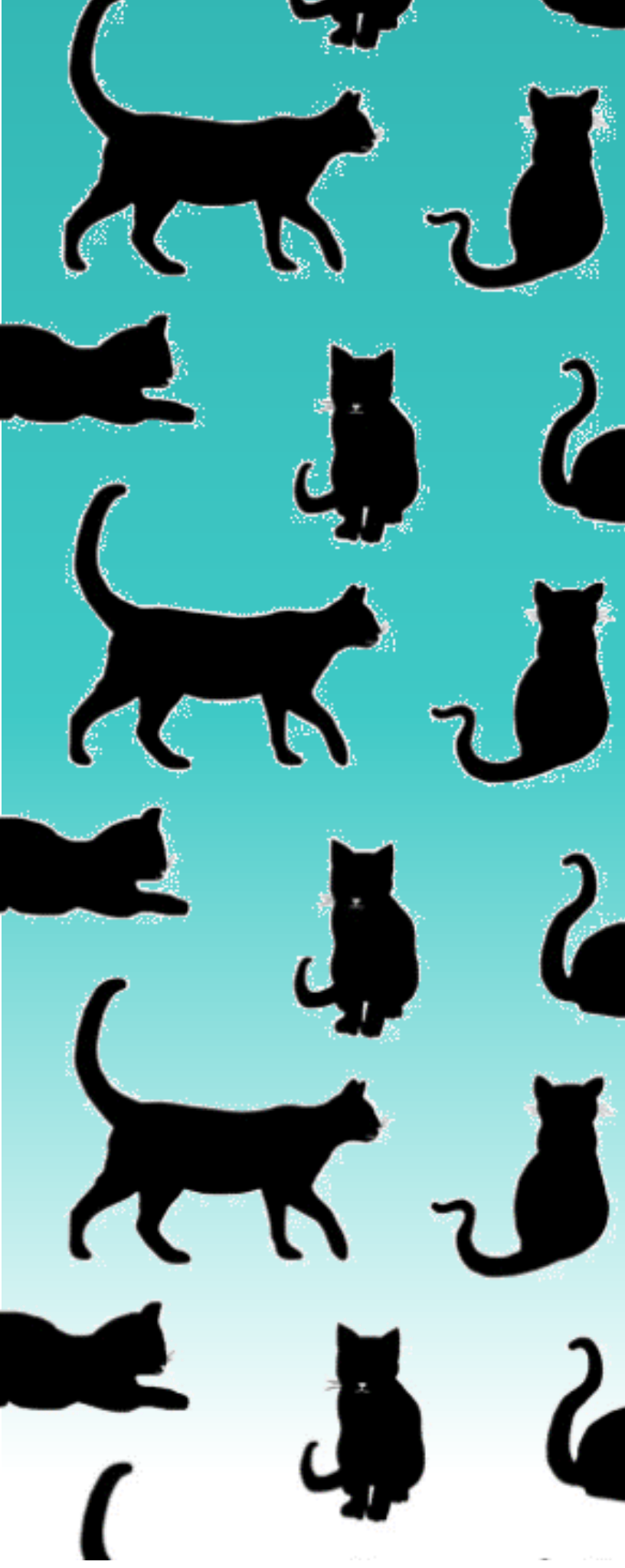


\section{O que é a Toxoplasmose???}

A toxoplasmose é uma Zoonose infecciosa e possui distribuição mundial (HILL, 2018). Ela é causada pelo protozoário Toxoplasma gondii. O parasita se multiplica dentro do intestino do gato e ao eliminar suas fezes, ele libera milhares de oocistos no ambiente. Esses oocistos contaminam o homem e outros mamíferos e aves (PORTEEN, 2018).

Os gatos são considerados um risco em potencial para transmissão da doença devido ao seu contato mais direto com o homem (ULLMANN et al., 2008). 
Figura 1. Potencial zoonótico da toxoplasmose: agente etiológico, hospedeiro definitivo (gato) e risco de infecção transplacentária em humanos.

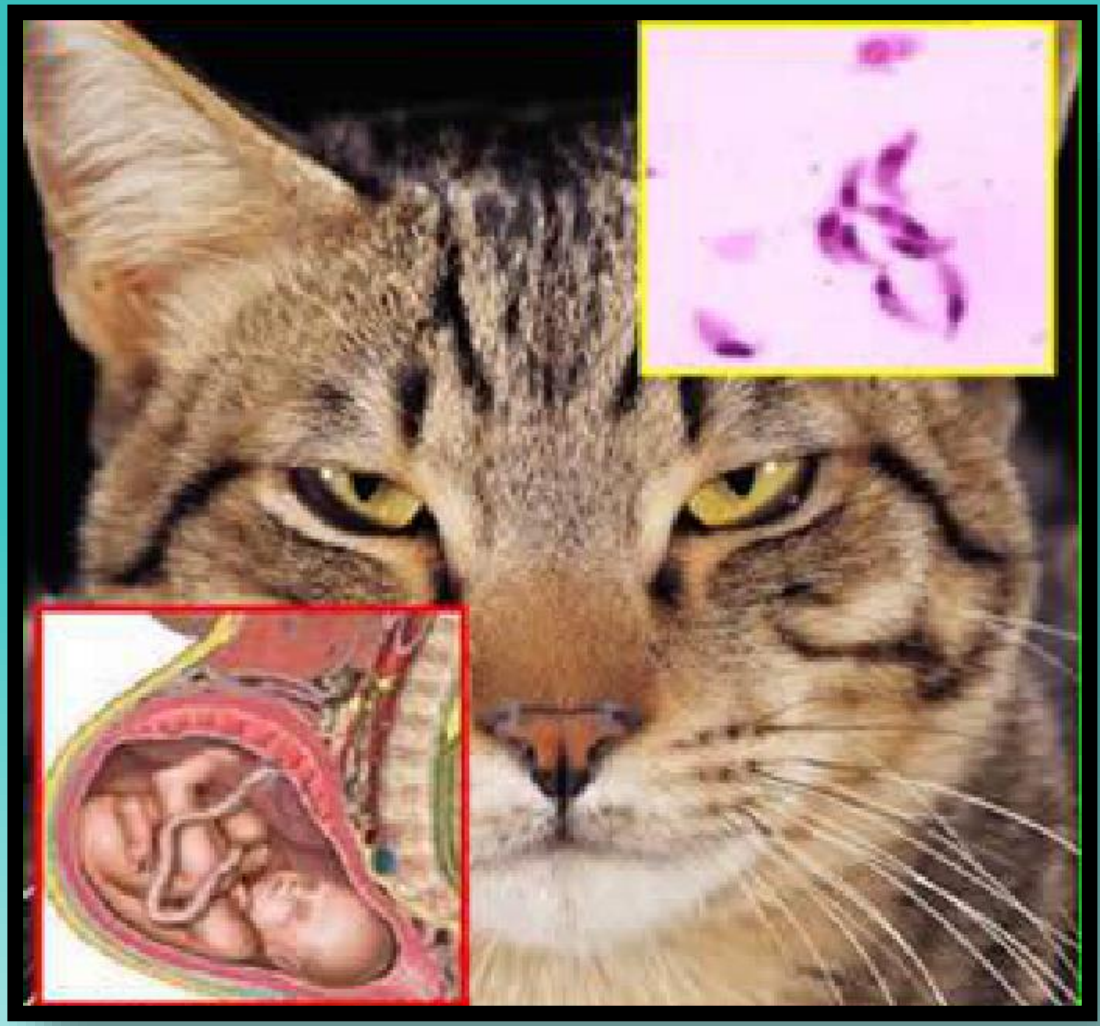

Fonte: http://www.ufrgs.br/parasite/siteantigo/Imagensatlas/Protozoa/Toxoplasma.htm 


\section{Era uma vez um parasita}

Esse parasita foi descoberto em 1908, por Splendore, em São Paulo, após a morte de coelhos infectados. No mesmo ano, Nicolle e Manceaux encontraram o parasita em um roedor africano utilizado em laboratório na Tunísia. A descoberta do parasita em dois continentes e espécies distintas fez perceber que este parasita estava em muitos lugares no mundo e podia infectar vários tipos de animais. Após essas descobertas em 1909, Nicolle e Manceaux criaram o gênero Toxoplasma e a espécie Toxaplasma gondii (AMATO NETO, 2014).

Os estudos sobre o Toxoplasma, até então encontrados somente em animais, espertaram interesse com os primeiros casos relatados em humanos. Pois em 1923, Janku informou o caso de uma criança, com 11 meses de idade, falecida em Praga. 
Foram vistos, em sua necropsia, parasitas semelhantes ao toxoplasma. Janku disse que seria o caso de uma infecção passada de mãe para filho durante a gestação. Em 1927 no Rio de Janeiro, Torres confirmou que esse tipo de infecção era possível (AMATO NETO, 2014).

Figura 2. Taquizoitos de T. Gondii.

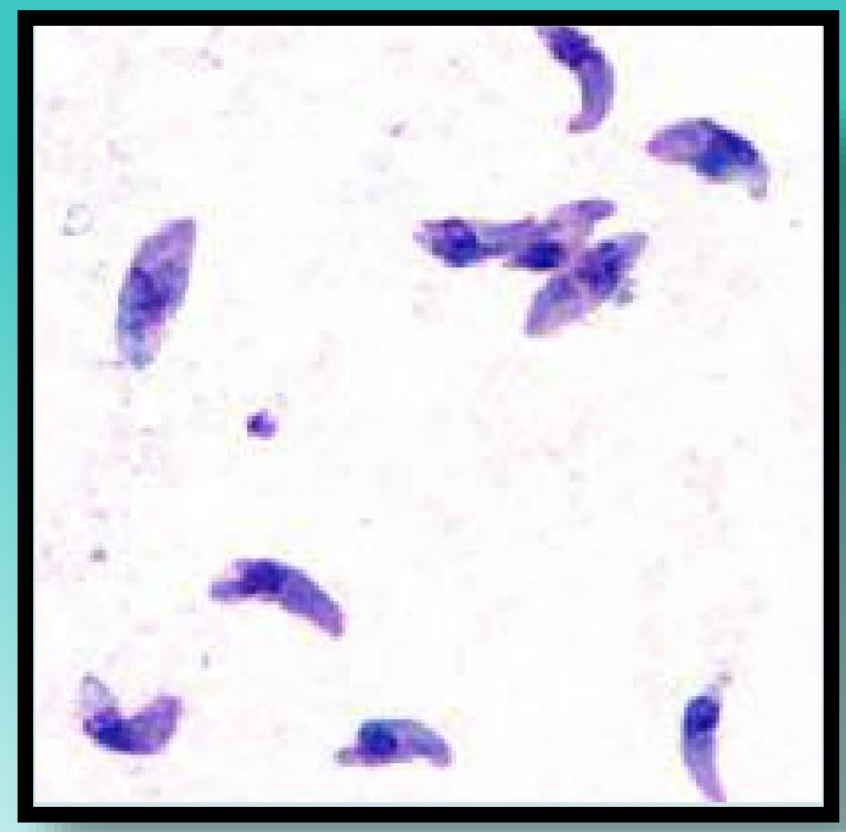

Fonte: http://www.ufrgs.br/para-

site/siteantigo/Imagensatlas/Protozoa/Toxoplasma.htm 
Em 1942, nos Estados Unidos, foi registrada a ocorrência da toxoplasmose em adultos e nesses casos, o parasita foi isolado. A partir daí começaram os estudos de técnicas utilizando o sangue como meio de descoberta do diagnóstico da toxoplasmose, chamados de exames sorológicos. Em 1948, foi inserida a prova de reconhecimento da doença em um teste de sensibilidade da pele a toxoplasmose. Os testes foram realizados em todo o mundo e muitos habitantes e várias espécies de animais foram encontrados com a presença de anticorpos contra o Toxoplasma. gondii. A presença desses anticorpos no sangue indicava que as pessoas já teriam sido infectadas com o parasita antes (AMATO NETO, 2014).

A partir da década de 1970 foi descoberto o hospedeiro definitivo do parasita, o gato e outros felinos. Nesse hospedeiro é que o parasita consegue se multiplicar. Vários estudiosos encontraram uma forma 
infectante e resistente do toxoplasma nas fezes de gato e, logo após, foi identificado o ciclo sexuado de Toxoplasma gondii no intestino do felino. Essa descoberta permitiu o melhor conhecimento sobre como a toxoplasmose se manifesta e é transmitida. (AMATO NETO, 2014).

Atualmente, é grande o número de espécies entre aves e mamíferos encontrados naturalmente infectados por Toxoplasma gondii, incluindo animais domésticos, de criação e que vivem aos arredores de domicílios sendo de vida selvagem livre ou mantidos em cativeiro (AMATO NETO,2014). 


\section{Me diga com quem tu andas que}

\section{digo quem tu és}

Esses protozoários pertencem ao Reino Protista, sub-reino Protozoa (do grego, protos: primeiro e zoon: animal) e são destacados em sete filos, destacando-se o Apicomplexa. Neste filo estão os considerados parasitas intracelulares obrigatórios, ou seja, que só sobrevivem dentro das células de um hospedeiro. Os parasitas desse filo em uma determinada fase de sua vida, possuem uma estrutura chamada complexo apical, composto por organelas secretoras especializadas. Essas organelas têm como função facilitar a entrada dos parasitas nas células hospedeiras. Dentro desse filo, destaca-se a família Sarcocystidae, dividindo-se ainda em subfamílias, sendo uma delas a Toxoplasmatinae, alocando vários gêneros, sendo um deles o Toxoplasma, tendo como única espécie Toxoplasma gondii (COSTA, 2013). 


\section{Cara - crachá}

Figura 3. Estrutura do taquizoíto de T. gondii.

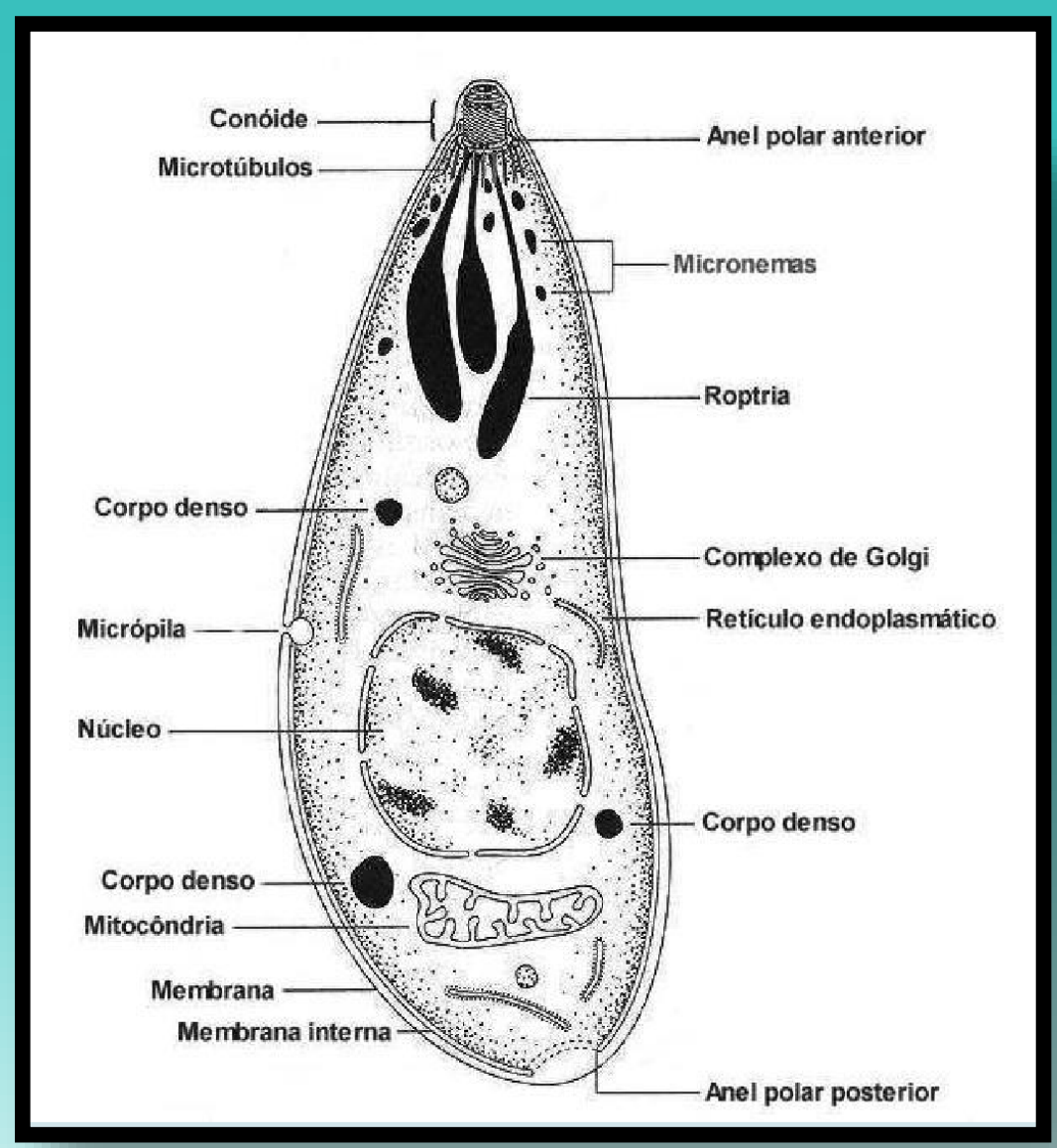

Fonte: Adaptado de (BAUM et al., 2006) 


\section{Crescei e multiplicai-vos!}

Esse protozoário possui três fases: taquizoítos, bradizoítos (cistos tissulares) e esporozoítos (oocistos). Possui ainda um ciclo biológico heteroxeno que significa que precisa de mais de um hospedeiro para completar o seu ciclo de vida. Todos os mamíferos e aves podem participar como hospedeiros intermediários que são necessários ao amadurecimento e os felinos como hospedeiros definitivos, onde irão se reproduzir (COSTA, 2013).

Todas as fases de desenvolvimento são infectantes para os hospedeiros, podendo adquirir toxoplasmose por vias distintas: via oral pela ingestão de oocistos esporulados no ambiente e ingestão de cistos pela carne crua ou mal cozida, e ainda, pela transmissão de taquizoítos de mãe para filho via placenta. Eles podem ser transmitidos também através 
do leite, de mãe para o filho, e por doações de órgãos ou sangue (COSTA, 2013).

Figura 4. Ciclo epidemiológico da toxoplasmose.

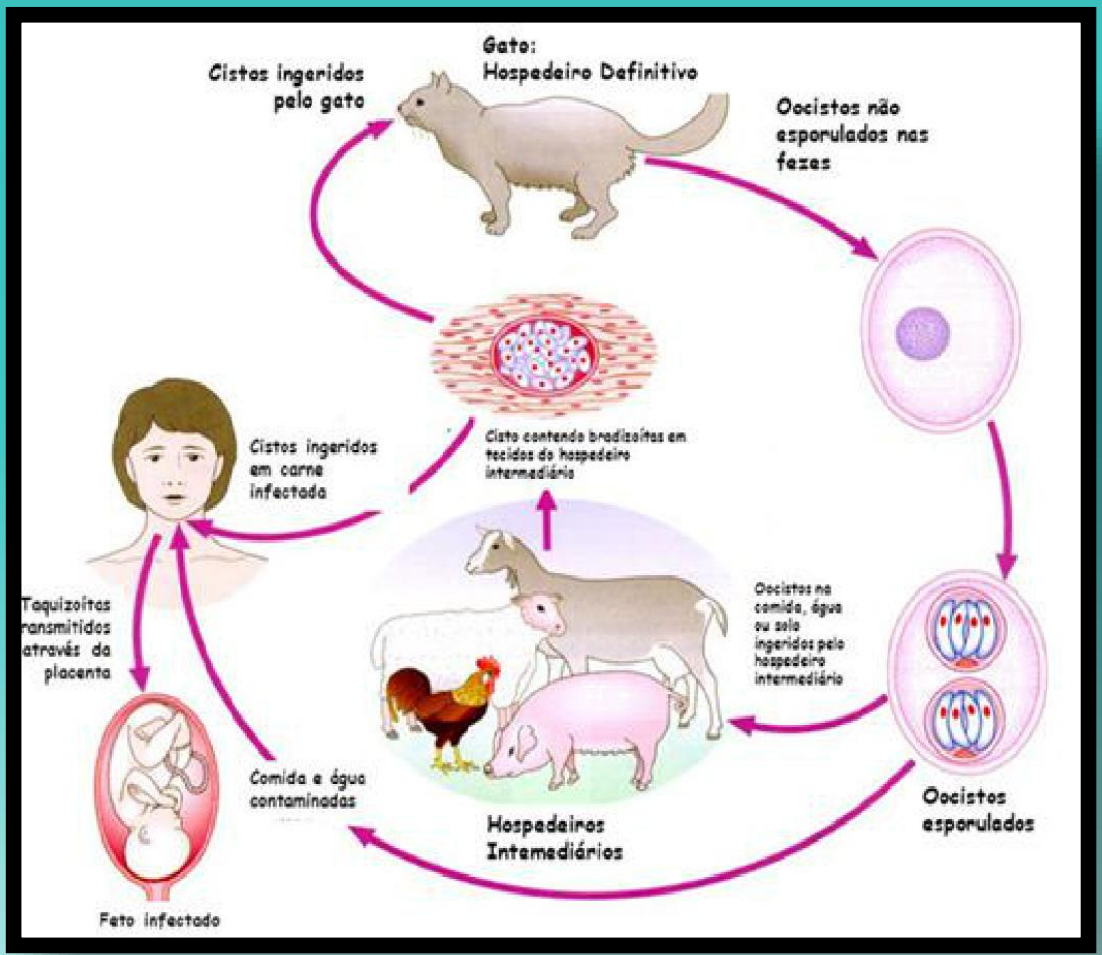

Fonte: $\underline{\text { http://atlasparasitologia.sites.uff.br/?cat=32 }}$ 


\section{Saiba como identificar e a qual seriedade dos sintomas}

Os estágios da doença são bastantes distintos, pode trazer complicações, como sequelas pela infecção congênita que é a infecção que ocorre de mãe para filho ainda durante a gestação. (MALDONADO, 2017).

Complicações como toxoplasmose ocular e toxoplasmose cerebral pode ocorrer também em pessoas que têm o sistema imunológico enfraquecido, como transplantados, pacientes infectados com o HIV ou em tratamento sintomas são variáveis e associados ao estágio da infecção se agudo que é uma infecção recente ou crônico que é uma infecção de longa duração (VILLARD, 2016). Normalmente os sintomas são leves e parecidos com os sintomas da gripe, dengue e podem incluir dores musculares e alterações nos gânglios linfáticos (WILKING, 2016). 
Gestantes: mulheres infectadas durante a gestação podem ter abortamento ou nascimento de criança com icterícia, macrocefalia, microcefalia e crises convulsivas (FALLAH, 2018).

Recém-nascidos: dos recém-nascidos infectados com a Toxoplasmose Congênita, cerca de 85\% dos casos não apresentam sinais clínicos evidentes ao nascimento.

Os recém-nascidos que apresentam manifestações clínicas podem ter sinais no período neonatal ou nos primeiros meses de vida. Esses casos costumam ter, com mais frequência, sequelas graves, como acometimento visual em graus variados, retardo mental, anormalidades motoras e surdez. As sequelas são ainda mais frequentes e mais graves nos recémnascidos que já apresentam sinais ao nascer, com comprometimento da visão em graus variados, retardo 
mental, crises convulsivas, anormalidades motoras e surdez (BRASIL, 2019).

Figura 5. Lesão cicatricial da toxoplasmose na região macular do olho causando perda da visão.

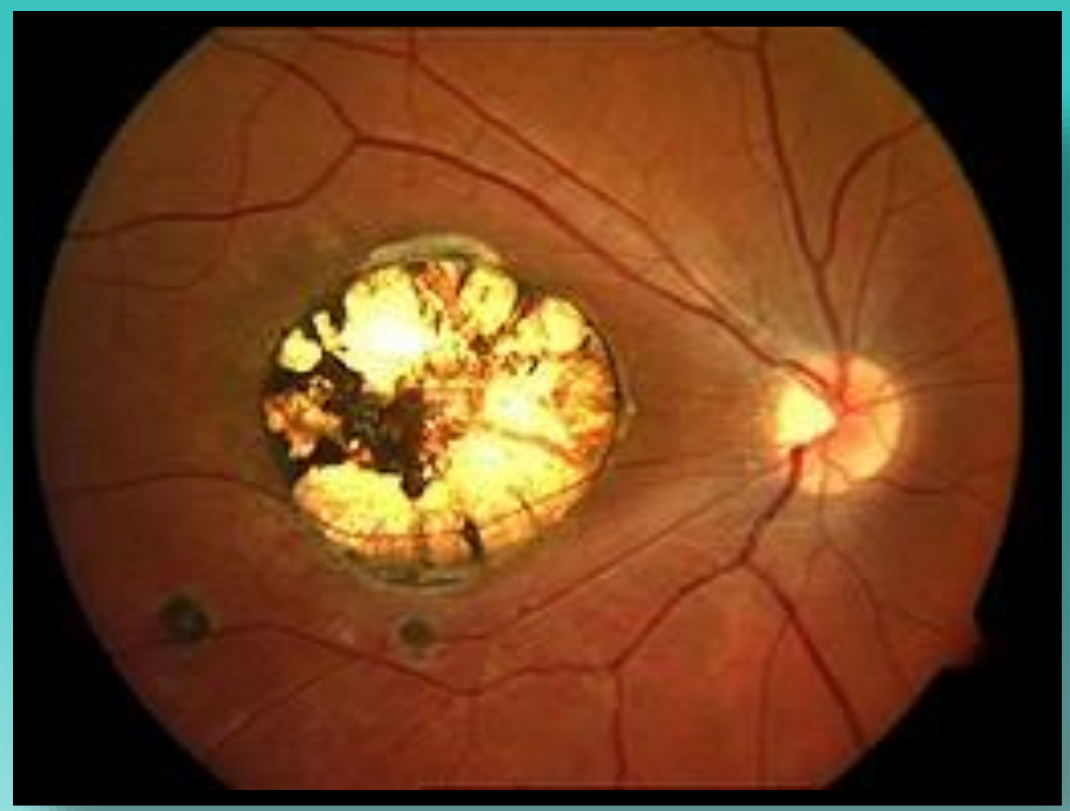

Fonte:https://www.institutoderetina.com.br/home/toxoplasm ose-ocular/ 


\section{Como seu médico confirma}

É coletado o histórico do paciente com uma entrevista e feito o exame físico. Quando os exames físicos sugerem toxoplasmose são feitos exames laboratoriais. Inicialmente pedido o Elisa que é um teste feito com o sangue para verificar a presença de os anticorpos para toxoplasmose na qual falamos anteriormente. Essa é a principal ferramenta de diagnóstico (DYE, 2019).

Os anticorpos IgM para o toxoplasma aparecem em alguns dias da infecção e podem ser detectados pelos exames sorológicos por até 18 meses após a infecção adquirida. Os anticorpos IgG aparecem em 1 a 2 semanas de infecção, atingem uma quantidade máxima e depois diminuem a taxas diferentes e persistem por toda a vida da pessoa. A presença desses 
anticorpos é que dirão se a infecção foi recente ou antiga. (DYE, 2019).

Se a paciente estiver grávida ou for imunocomprometida (HIV e outros) são feitos teste para identificação histológica e utiliza-se a técnica de Reação em Cadeia da Polimerase (PCR) para identificação do parasita (NICHOLAS; COLLINS; LUKAS, 2017).

O DNA do parasita pode ser detectado pela reação em cadeia da polimerase em amostras de biópsia de linfonodos, líquido cerebrospinal, amostras de escarro, se houver suspeita de toxoplasmose pulmonar, amostras vítreas e aquosas (DYE, 2019).

Na interpretação do teste sorológico é importante identificar se a gestante tem uma infecção recente ou antiga. Isso é feito através da identificação de 
anticorpos IgG positivo e IgM negativo sendo assim uma infecção crônica. Já IgM positivo e IgG negativo indica uma infecção aguda (CANTOS, 2000).

Para o feto, são obtidas uma ultrassonografia fetal e uma amniocentese se a infecção primária materna for diagnosticada ou não puder ser excluída ou se houver achados anormais de ultrassonografia do feto como calcificação intracraniana, microcefalia, hidrocefalia, ascite, hepatoesplenomegalia. Toxoplasma gondii no líquido amniótico pode ser detectado por PCR, com boa sensibilidade e especificidade após 18 semanas de gestação (DYE, 2019)

Em recém-nascidos com suspeita de toxoplasmose, é feito o teste sorológico IgM e IgA, pois os anticorpos lgG podem ser maternos já que a resposta imune do recém-nascido ainda é lenta e não 
teve tempo de produzir anticorpos IgG (CANTOS, 2000).

Se houver suspeita de toxoplasmose ocular, é realizado um exame oftalmológico completo (CANTOS, 2000).

Em pacientes infectados pelo HIV, ou seja, imunocomprometidos com toxoplasmose são quase uniformemente soropositivos para anticorpos antiToxoplasma IgG. A reativação ocorre como consequência da imunidade celular prejudicada e frequentemente causa encefalite. A tomografia computadorizada ou ressonância magnética do cérebro pode avaliar sintomas neurológicos e lesões sugestivas são vistas quando há encefalite toxoplasmática (NICHOLAS; COLLINS; LUKAS, 2017). 


\section{De olho nos cuidados e fazendo o tratamento}

O tratamento e acompanhamento da doença estão disponíveis, de forma integral e gratuita, pelo Sistema Único de Saúde (SUS). Em caso de toxoplasmose na gravidez, é importante o acompanhamento no pré-natal e a prática das orientações que forem repassadas pelas equipes de saúde (BRASIL, 2019).

A toxoplasmose normalmente evolui sem sequelas em pessoas com boa imunidade, desta forma não se recomenda tratamento específico, apenas tratamento para combater os sintomas. Pacientes com imunidade comprometida ou que já tenham desenvolvido complicações da doença (cegueira, diminuição auditiva) são encaminhados para acompanhamento médico especializado (BRASIL, 
2019). Porém, o tratamento é indispensável para os pacientes sintomáticos, imunossuprimidos e para as gestantes, pois a forma disseminada da doença pode provocar complicações graves e levar a óbito.

Medicamentos como a pirimetamina (usado também contra a malária) associado a um antibiótico específico e ao ácido fólico já se mostraram úteis para o tratamento da toxoplasmose, porque impedem a multiplicação do protozoário nas formas mais agressivas da doença. É importante que eles sejam prescritos por um médico que acompanhe de perto a evolução do quadro (BRUNA, 2016).

Em se tratando de toxoplasmose congênita, a maioria dos recém-nascidos infectados durante a gestação são assintomáticos. Sem diagnóstico e tratamento adequado, muitos desenvolverão sequelas graves da infecção que pode causar complicações 
cerebrais, neurológicas, visuais, auditivas, renais, hepáticas e retardo mental (BRUNA, 2016).

No entanto, o risco de passar a infecção para o feto desaparece, quando a mãe apresenta sorologia positiva contra o Toxoplasma gondii, porque desenvolveu anticorpos contra ele.

Isso significa que ela já foi infectada pelo protozoário a muito tempo e que os anticorpos permanecem adormecidos no tecido muscular e nervoso, mas é controlado pelo sistema imune. Portanto, não oferece risco de passar a infecção para o feto. Para isso medidas educativas de boas práticas de higiene e manuseio das fezes dos felinos devem ser redobradas, para evitar o contato inicial com a doença (BRUNA, 2016). 


\section{MEU GATO NÃO É O VILÃO}

Diante de tantas informações a respeito da toxoplasmose, devemos adotar medidas preventivas simples e assim levar uma vida saudável com quem nós tanto amamos!!!

Quadro 1. Atitudes preventivas contra a toxoplasmose

1. Evitar consumir carnes cruas ou malcozidas.

2. Lavar muito bem as mãos antes das refeições.

3. Após contato com animais domésticos, lavar sempre as mãos.

4. Lavar bem verduras, frutas e hortaliças.

5. Nunca forneça para seu bichinho de estimação carnes cruas.

6. Lave sempre as mãos ao realizar serviço de jardinagem.

7. Mantenha as rações de seus animais sempre protegidas e guardadas em local fresco e arejado.

8. A caixinha onde seu gatinho faz as necessidades sempre deve manter-se limpa.

Leve seu bichinho de estimação com periodicidade para o Médico-Veterinário 


\section{Referências Bibliográficas}

AMATO NETO, Vicente. Prefácio. In: SOUZA, Wanderley de; BELFORT JUNIOR, Rubens.

Toxoplasmose \& Toxoplasma gondii. Rio de Janeiro:

Fiocruz, 2014. p. 14-15.

BRASIL. MINISTÉRIO DA SAÚDE. (Org.). Toxoplasmose: sintomas, tratamento e como prevenir. 2019. Disponível em: <http://saude.gov.br/saude-de-az/toxoplasmose>. Acesso em: 18 nov. 2019.

BRUNA, Maria Helena Varella. Doenças e Sintomas: Toxoplasmose. 2016. Disponível em: $<$ https://drauziovarella.uol.com.br/doencas-esintomas/toxoplasmose-3/>. Acesso em: 18 nov. 2019.

CANTOS, G. A. et al. Toxoplasmose: ocorrência de anticorpos antitoxoplasma gondii e diagnóstico. Rev. Assoc. Med. Bras., São Paulo, v. 46, n. 4, p. 335-341, Out. 2000. Disponível em: <http://www.scielo.br /scielo.php?script=sci_arttext\&pid=S0104$42302000000400033 \&$ lng=en \&nrm=iso>. Acesso em 18 Nov. 2019.

COSTA, Rebeka Cristine de Bastos. Aspectos biológicos, epidemiológicos, clínicos e de diagnóstico do Toxoplasma gondii. 2013. 31 f. Pós-graduação - 
Curso de Ciência Animal, Escola de Veterinária e Zootecnia, Universidade Federal de Goiás, Goiania, 2013. Disponível em:

http://www.ppgca.evz.ufg.br/up/67/o/toxoplasma_se min\%C3\%A1rio.pdf. Acesso em:

03 nov. 2019.

DYE, Leslie R. (Ed.). Clinical Overview: Elsevier Point of Care. 2019. Disponível em:

<https://www.clinicalkey.com/\#!/content/clinical_ove rview/67-s2.0-1e23d0e6-7351-41e3-88d0-

$5 c d f e b a 11 c f 4$ ?scrollTo=\%23diagnostic-proceduresheading-19>. Acesso em: 18 nov. 2019.

FALLAHI, Shirzad et al. An updated literature review on maternal-fetal and reproductive disorders of Toxoplasma gondii infection. Journal of gynecology obstetrics and human reproduction, v. 47, n. 3, p. 133140, 2018.

HILL, Dolores E.; DUBEY, Jitender P. Toxoplasma gondii as a parasite in food: analysis and control. Preharvest Food Safety, p. 227-247, 2018.

MALDONADO, Yvonne A. et al. Diagnosis, treatment, and prevention of congenital toxoplasmosis in the United States. Pediatrics, v. 139, n. 2, 2017. 
NICHOLAS, M. Kelly; COLLINS, John; LUKAS, Rimas V..

Acquired Immunodeficiency Syndrome. In: WINN, H. Richard (Ed.). Neurological Surgery. 7. ed.

Philadelphia: Elsevie, 2017. Cap. 41. p. 223-241.

PORTEEN, K.; RUBAN, S. Wilfred; QUINTOIL, Nithya. Foodborne Parasites: One Health

Perspective. Research Methodology in Food Sciences: Integrated Theory and Practice, p. 41, 2018.

ULLMANN, Leila S. et al. Ações de vigilância continuada, papel do cão como animal sentinela para toxoplasmose. Revista Brasileira de Parasitologia

Veterinária, Jaboticabal, Brasil, v. 17, n. 1, p.345-347, set. 2008. Disponível em: https://www.redalyc.org/pdf/3978/397841469071. pdf. Acesso em: 03 nov. 2019.

VILLARD, O. et al. Serological diagnosis of Toxoplasma gondii infection: recommendations from the French National Reference Center for Toxoplasmosis. Diagnostic Microbiology and Infectious Disease, v. 84, n. 1, p. 22-33, 2016.

WILKING, Hendrik et al. Prevalence, incidence estimations, and risk factors of Toxoplasma gondii infection in Germany: a representative, crosssectional, serological study. Scientific reports, v. 6, p. 22551, 2016. 


\section{Autores}

\section{Maria Verônyca Coelho Melo}

Lattes: http://lattes.cnpq.br/3825083818114123

Membro do corpo editorial da Revista de Nutrição e Vigilância em Saúde (Nutrivisa/2014). Possui graduação em Enfermagem Bacharelado pela Universidade Estadual do Ceará (1997), e graduação em Enfermagem Licenciatura pela Universidade Estadual do Ceará (1998). Especialização em Educação Profissional na Área de Saúde: Enfermagem, pela Fundação Oswaldo Cruz (FIOCRUZ) (2004), Especialização em Enfermagem Médico- Cirúrgica, pela Universidade Estadual do Ceará (1999). Doutorado em Biotecnologia (RENORBIO) pela Universidade Estadual do Ceará (2011). Docente nos cursos de enfermagem e nutrição da disciplina de parasitologia e metodologia do ensino dos cursos de nutrição, biomedicina e enfermagem pelo Centro Universitário Christus Unichristus. Docente do curso de biologia do ensino a Distância da Universidade Aberta do Brasil - UAB da Universidade Estadual do Ceará - UECE. Tem experiência nas seguintes áreas: Microbiologia, Biotecnologia, Parasitologia e, Helmintologia. 


\section{Alessandra Marinho da Silva}

\section{Lattes: http://lattes.cnpq.br/8566139322864223}

Estudante de graduação em Enfermagem pelo Centro Universitário Christus, cursando o $5^{\circ}$ semestre. Aluna de Iniciação Científica na mesma instituição no Projeto "Perfil das Vulnerabilidades Sociais e Biológicas em Crianças Menores de Um Ano Atendidas na Consulta de Puericultura". Graduada em Química pela Universidade Estadual do Ceará no ano de 2015. Foi aluna bolsista de Iniciação Científica PROVIC no Projeto "Caracterização Química e Biotecnológica dos Méis e Pólen Produzidos por Melipona Subnitida d. no Ceará" e bolsista de Iniciação à Docência pela Coordenação de Aperfeiçoamento de Pessoal de Nível Superior - CAPES no projeto "Ações Construtivas do Conhecimento de Química nas Escolas Públicas". 


\section{Dalyla Uchôa Cavalcante}

Lattes: http://lattes.cnpq.br/7412261409305602

É estudante do curso de Enfermagem (Bacharelado) na instituição Centro Universitário Christus - Unichristus. Ensino médio cursado no Escola de Ensino Fundamental e Médio Dona Júlia Alves Pessoa. Nascida e residente em Fortaleza, Ceará. 


\section{Nívia Barbosa Rocha \\ Orcid: https://orcid.org/0000-0001-6822-9205}

Estudante graduanda em Bacharelado em Enfermagem, no Centro Universitário Christus Unichristus, cursando $5^{\circ}$ semestre. Ensino médio cursado na escola Polivalente Modelo de Fortaleza e concluído no Centro Educacional para Jovens e Adultos - CEJA. Atualmente autônoma. Nascida e residente em Fortaleza. 


\section{Silvia Helena Lobo Sousa}

\section{Lattes: http://lattes.cnpq.br/1720799686709997}

É graduada em Licenciatura em Educação Física pelo Instituto Federal de Educação, Ciência e Tecnologia do Ceará e foi bolsista de Iniciação à Docência- PIBID, pela Coordenação de Aperfeiçoamento de Pessoal de Nível Superior - CAPES. Acadêmica em Enfermagem pelo Centro Universitário Christus. 


\section{Felipe Dourado de Aragão Pinheiro}

Lattes: http://lattes.cnpq.br/5260329185297452

Possui graduação em Medicina Veterinária pela Universidade Estadual do Ceará - UECE. Especialização em VIGILANCIA SANITÁRIA DE ALIMENTOS pela Universidade Estadual do Ceará-UECE. Mestre em ciências veterinárias pelo programa de pós-graduação em Medicina Veterinária da Universidade Estadual do Ceará. Atualmente ocupa o cargo de Assessor técnico da Fiscalização do Conselho Regional de Medicina Veterinária do estado do Ceará. 


\section{Alexsandre Fernandes Ribeiro}

Lattes: http://lattes.cnpq.br/8586323462805190

Possui Especialização em GESTÃO E AVALIAÇÃO DA ESCOLA PÚBLICA pelo Centro de Políticas Públicas e Avaliação da Educação - CAED /UFJF; Aperfeiçoamento em ECOTURISMO pela Universidade Estadual do Ceará; Graduação em CIÊNCIAS BIOLÓGICAS pela Universidade Estadual do Ceará. Atualmente é Professor da Universidade Estadual do Ceará (UECE/UAB/EaD) no Curso Química. Professor na Universidade Estadual Vale do Acaraú (UVA), através dos Institutos IDJ e IDECC desde 2007 na Graduação e Pós-Graduação. Lecionou no Instituto Superior Cearense, nos Cursos de Pedagogia e Serviço Social; Lecionou na Pós-graduação no Instituto Plenitude de Desenvolvimento Educacional Continuada - IPDEC vinculado à FALC (Faculdade da Aldeia de Carapicuíba) e a FMB (Faculdade Maciço de Baturité). Professor Efetivo de Biologia e Ciências da Secretaria do Estado do Ceará (SEDUC-CE). Tem experiência na área de Biologia Geral, Meio Ambiente, Ecoturismo, Educação, Gestão e Avaliação Educacional. Atuou como Diretor e Coordenador Escolar. 

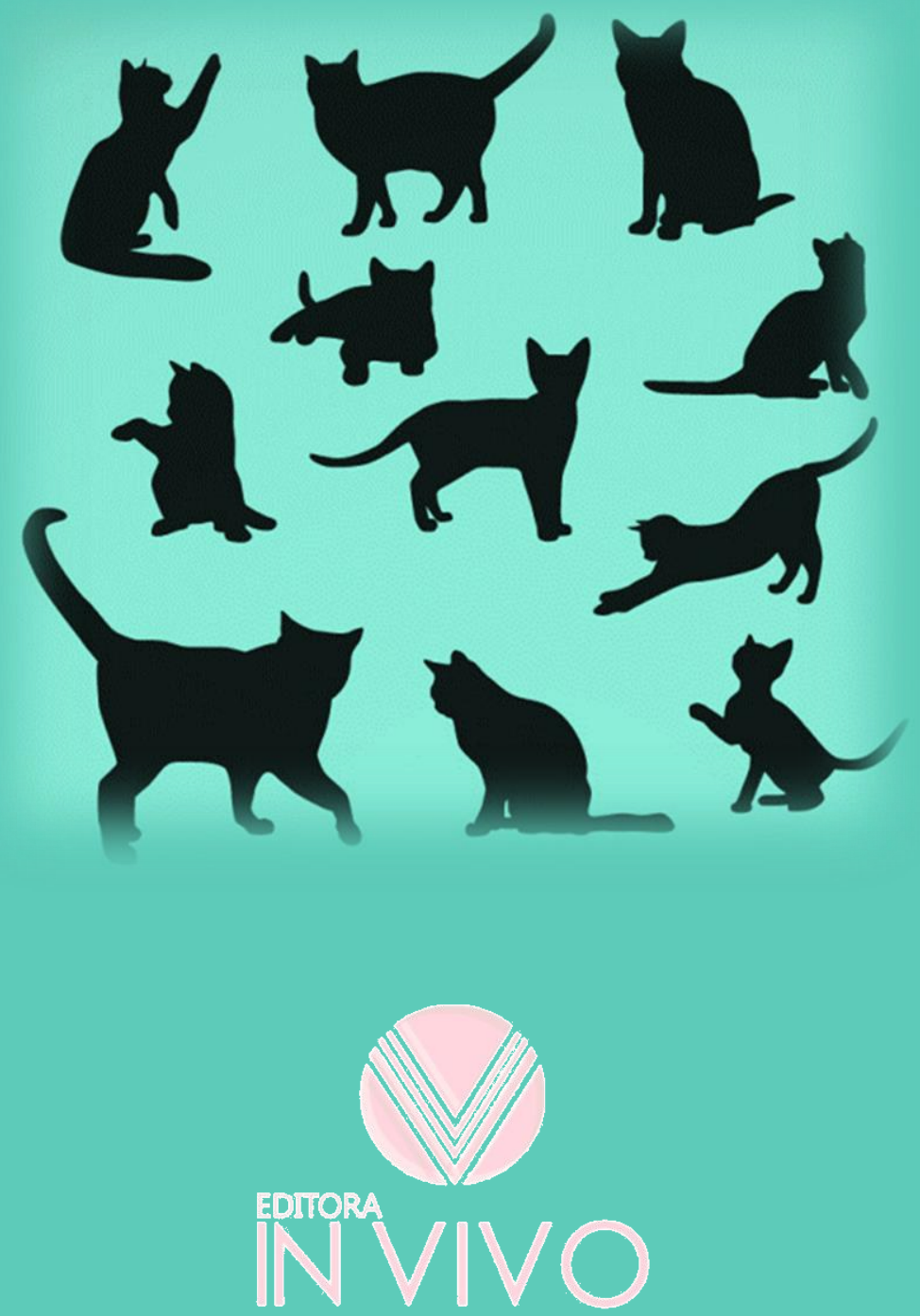